\title{
Aplicación de las Comunicaciones Inalámbricas a la Domótica
}

* Ingeniero Electrónico - Grupo de Arquitecturas Digitales y Microelectrónica - Escuela de Ingeniería Eléctrica y Electrónica Facultad de Ingeniería - Universidad del Valle, Santiago de Cali, Colombia. E-mail:ingevera@hotmail.com

** Ingeniero Electrónico - Grupo de Arquitecturas Digitales y Microelectrónica - Escuela de Ingeniería Eléctrica y Electrónica Facultad de Ingeniería - Universidad del Valle, Santiago de Cali, Colombia. E-mail:alarcon27@hotmail.com

$\star \star \star$ Especialista, Ingeniero Electricista - Profesor Escuela de Ingeniería Eléctrica y Electrónica - Facultad de Ingeniería Universidad del Valle, Santiago de Cali, Colombia.

E-mail:opolanco@univalle.edu.co

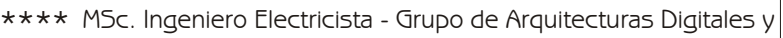
Microelectrónica - Escuela de Ingeniería Eléctrica y Electrónica Facultad de Ingeniería - Universidad del Valle, Santiago de Cali, Colombia. E-mail:rnieto@univalle.edu.co

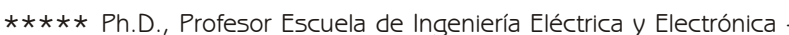
Facultad de Ingeniería - Universidad del Valle, Santiago de Cali, Colombia. E-mail:alvaro@univalle.edu.co

Fecha de recepción: Moviembre 25 de 2003

Fecha de aprobación: Abril 30 de 2004

\author{
Alexander Vera T.* \\ Andrés Alarcón R.** \\ Oscar Polanco M.*** \\ Rubén D. Mieto L.**** \\ Álvaro Bernal M.*
}

\section{RESUMEN}

Este artículo muestra un modelo que permite el control de Electrodomésticos a través de la integración de los protocolos X-10 y WAP. Para esto, se ha definido un modelo, en el que un usuario puede modificar el estado de sus electrodomésticos (Prender y Apagar) por medio de un teléfono móvil celular. Además, se muestra el diseño e implementación de los módulos electrónicos, que se ajustan a las características establecidas por el protocolo $X-10$. 
Palabras Clave: Protocolo $X-10$, Domótica, Servidor, Microcontrolador, Base de Datos.

\section{ABSTRACT}

The article presents a model to control electrical appliances using both $X-10$ and WAP protocols. In this model a user can modify the state (OMOFF) of electrical appliances by using a wireless phone. The article also presents a design and implementation of electronic modules following the guidelines established by the $X-10$ standard.

Key Words: X-10 Protocol, Domotics, Server, Microcontroller, Data Base.

\section{INTRODUCCIÓN}

La globalización de la Internet ha contribuido al desarrollo de tecnologías que faciliten el acceso a ella. Actualmente, las comunicaciones inalámbricas han sido adaptadas con este enfoque para el acceso remoto a información disponible en la red de redes; tal es el caso de los teléfonos móviles, a los que se les ha incorporado un micronavegador, a través del cual el usuario puede consultar en la Internet.

Por otra parte, han surgido numerosas aplicaciones que se soportan en esta plataforma, y permiten la modificación y consulta en línea de variables, parámetros y datos en general. Entre estas aplicaciones está la domótica, que se ha consolidado rápidamente debido al uso de medios de transporte de información ya establecidos, como la red eléctrica, la red telefónica y las redes de área local.

La domótica, considerada como una disciplina diseñada para el control de electrodomésticos de uso común desde un lugar remoto a la casa, utiliza tecnologías estandarizadas que facilitan su desarrollo. El protocolo $X-10$ es una de estas tecnologías, y determina las condiciones para transmitir información a través de la red eléctrica; además, se ha convertido en la base de los sistemas domóticos.
La incorporación de nuevas formas de transmitir información de control, buscando siempre la implementación en tecnologías de uso masivo, ha permitido el fortalecimiento de la domótica. En la actualidad, la utilización de teléfonos móviles, podría facilitar el control remoto de electrodomésticos, gracias a la existencia de un protocolo de comunicación (WAP Wireless Application Protocol) que le permite al usuario acceder a los servicios de la Internet desde su teléfono móvil.

\section{LOS PROTOCOLOS X-10 Y WAP}

El protocolo $X$-10, utiliza la red eléctrica como medio de transporte para establecer comunicación entre un módulo de transmisión y uno de recepción, los cuales se encuentran conectados directamente a la red eléctrica. Los datos son transportados a través de la red $A C$ ( 60 Hz en USA 50 Hz en Europa). La sincronización entre los módulos se hace a partir de la detección de cruces por cero, donde puede encontrarse una trama de datos $X$-10 válida.

El protocolo $X$-10 define un formato de datos binario, en el que un " 1 " se representa por la presencia de un pulso (señal senoidal emitida durante $1 \mathrm{~ms}$, a partir de un cruce por cero y con frecuencia $120 \mathrm{kHz}$ ) en el semiciclo positivo de la señal de la red eléctrica, seguido por la ausencia del mismo en el siguiente semiciclo. De la misma manera, un " 0 " se representa como la ausencia de pulso seguido por la presencia del mismo en un ciclo (ver figura 1 ).

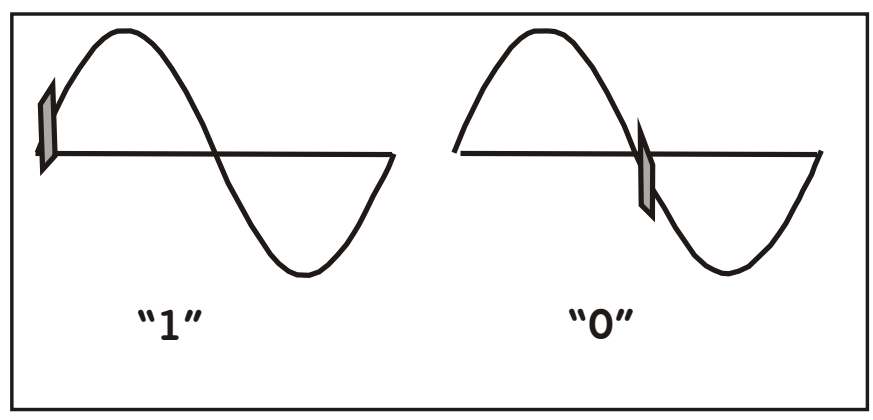

Figura 1. Representación de los niveles lógicos en el protocolo $\mathrm{X}-10$ 
La información que se transmite es precedida por un código de inicio "Start Code", representado como tres pulsos consecutivos en dos semiciclos. Luego del start code, se envían 4 bits que se conocen como código de carta (Letter (ode), que permite seleccionar un grupo de receptores que hacen parte de un conjunto global. Después del código de carta se envían otros cuatro bits que se conocen como código numérico (Mumber Code) cuya función es seleccionar un único receptor del conjunto local al cual pertenece. Seguidamente debe aparecer un bit con un nivel lógico de " 1 ", informando al receptor que se ha enviado la primera trama de datos. Al finalizar el envío de una trama de datos, debe haber una retransmisión de la misma.

Cuando ha ocurrido la retransmisión del primer "frame", deben aparecer tres ciclos de la onda senoidal sin envío de pulsos; esto con el objeto de mandar otra secuencia de datos en los cuales se introduce la función que se desea realizar.

La segunda secuencia consta de dos ciclos de la onda seno en la cual se manda nuevamente el código de inicio. Después, se envían cuatro bits que representan el código de carta, y luego se envían 4 bits que representan el comando que se desea ejecutar. Posteriormente se manda un bit en " 1 " para informar que la secuencia se ha completado.

Esta última secuencia se envía nuevamente como ocurría en el primer caso (ver figura 2).

\begin{tabular}{|c|c|c|c|c|c|c|c|c|c|c|c|c|}
\hline 2 & & 5 & 2 & 4 & 5 & 3 & 2 & 4 & 5 & 2 & 4 & 5 \\
\hline
\end{tabular}

Figura 2. Representación de la trama

de datos en $\mathrm{X}$-10

El protocolo $X$-10 es capaz de identificar 256 receptores por cada transmisor, a través del código de carta y el código de letra.

Con el código de comando se permite el control de un determinado electrodoméstico (o de un grupo de ellos), con funciones como encendido o apagado. Estas señales las reciben todos los módulos, pero sólo actúa sobre aquel al que va dirigida.

Para enviar las señales de control a través de la red eléctrica se requiere de un sistema inteligente que reciba los mandos del usuario y los analice con el fin de conocer su destino. Esta labor es efectuada por un computador que se encuentra en permanente contacto con los diferentes usuarios por medio de la Internet.

Los usuarios pueden acceder al servicio por medio de un teléfono móvil, el cual debe tener incorporada una interfaz que brinde las opciones a las que se puede acceder, como por ejemplo, los electrodomésticos a controlar.

El enlace del teléfono móvil con Internet se realizaría con el propósito de permitir la transmisión de datos (mandos) desde el usuario hasta el sistema inteligente. El WAP (Wireless Applications Protocol) es un protocolo estandarizado, que permite a los teléfonos móviles, convertidos en terminales, enviar y recibir datos a alta velocidad, tener acceso a Internet, correo electrónico, mantener una videoconferencia 0 , inclusive, realizar operaciones de comercio electrónico.

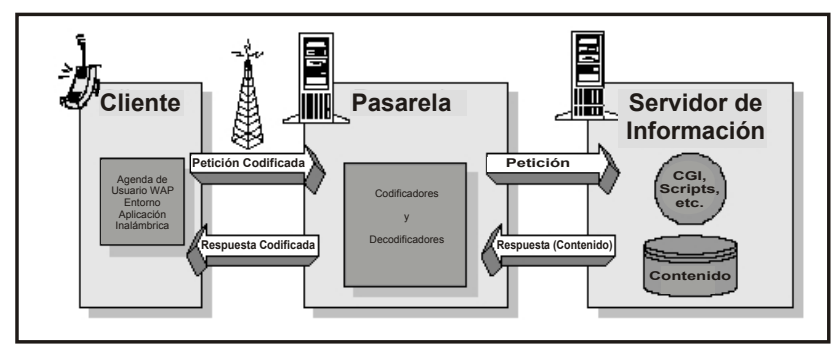

Figura 3. Esquema básico de la arquitectura WAP

En el terminal móvil debe existir un "micronavegador", el cual hace peticiones de información a una pasarela (gateway) que son adecuadamente tratadas y redirigidas al servidor de información correspondiente. Este servidor 
evalúa la solicitud de información y, una vez procesada, la envía de regreso a la pasarela que le da el formato adecuado para transmitir al terminal móvil. El lenguaje utilizado es el WML (Wireless Markup Languaje), una versión de HTML (Hypertext Markup Languaje).

Para garantizar la consistencia de la comunicación entre el terminal móvil y los servidores de red que proporcionan la información, WAP define un conjunto de componentes estándar:

■ Un modelo de nombres estándar. Se utilizan las URLs definidas en WWW para identificar los recursos locales del dispositivo (tales como funciones de control de llamada) y las URLs (también definidas en el WWW) para identificar el contenido WAP en los servidores de información.

■ Un formato de contenido estándar, basado en la tecnología WWW.

■ Unos protocolos de comunicación estándares, que permitan la comunicación del micro-navegador del terminal móvil con el servidor Web en red.

El terminal móvil tiene dos posibilidades de conexión: a un proxy WAP, o a un servidor WTA. EI proxy WAP traduce las peticiones WAP a peticiones Web, de forma que el cliente WAP (el terminal inalámbrico) pueda realizar peticiones de información al servidor Web. Por otra parte, el Servidor WTA (Wireless Telephony Application) proporciona acceso WAP a las facilidades ofrecidas por la infraestructura de telecomunicaciones del proveedor de conexiones de red.

\section{MODELO DE INTEGRACIÓN DE LOS PROTOCOLOS X-10 Y WAP}

La filosofía del modelo mostrado en la figura 4 es permitir la manipulación de electrodomésticos a un usuario de forma remota. El usuario debe poseer un teléfono móvil con micro navegador para permitir el acceso a la información de Internet.

Cuando se realiza una acción de control sobre un electrodoméstico, se establece una comunicación entre el terminal móvil y un servidor a través de una pagina WAP, la cual está en un formato que interpreta correctamente el micro navegador del terminal móvil. A través de esta página se solicita la identificación del usuario (login y password), para ser validada en una base de datos, que se encuentra en el servidor. Si el acceso ha sido autorizado al usuario, él puede solicitar el encendido / apagado de uno o varios de los electrodomésticos a controlar.

El tipo de servidor empleado es Apache, el cual puede configurarse para permitir el acceso a páginas que estén en formato WML y PHP. EI primero es el lenguaje de marcas estándar que permite la visualización de texto y demás mensajes estáticos en páginas de Internet de uso exclusivo de usuarios de telefonía móvil. El segundo es un lenguaje que funciona de forma embebida en código WML, con el propósito de ofrecer un mayor dinamismo e interactividad con las páginas elaboradas en WML. Además, este lenguaje facilita la integración con una base de datos. Los fragmentos de código PHP, insertados 
en una página WML, se ejecutan por medio de un compilador PHP que se encuentra instalado en el servidor.

En el servidor se ejecuta permanentemente un programa que se encarga de atender las solicitudes realizadas por el usuario. Con este programa se consulta la base de datos, determinándose la identidad del usuario y el tipo de solicitud. El programa se comunica con un módulo físico de transmisión, enviándole las direcciones que identifican al usuario y los electrodomésticos a controlar, así como las acciones que se van a llevar a cabo sobre los mismos.

El módulo de transmisión procesa la información entregada por el programa para generar una trama de datos que cumpla con las especificaciones del protocolo $X-10$, e inyecta esa codificación en la red eléctrica.

La red eléctrica es analizada constantemente por un módulo físico de recepción, el cual determina la presencia de un código $X$-10 válido.

Cuando el receptor detecta la presencia de un código $X-10$, recupera los campos de la trama que identifican al usuario, electrodoméstico y función de control. Además, compara la información recibida con la almacenada en su memoria, para determinar si la orden ha sido dirigida a él; de ser así, realiza la acción que se le ha indicado (prender/apagar el electrodoméstico a su cargo).

\section{ESTRUCTURA DE LA BASE DE DATOS}

Para este proyecto se diseña una base de datos sobre MYSQL, que contiene información clasificada de los usuarios quienes tienen acceso al servicio, y de los electrodomésticos que pueden manipular. Son creadas dos tablas, una de las cuales contiene información propia del usuario, que permite identificarlo; y la otra tabla suministra la identificación de los electrodomésticos y las acciones a realizar sobre ellos.

En la primera tabla (figura 5), el campo "Número" es una identificación del registro correspondiente de cada usuario. Los campos "Mombre" y "Apellidos" almacenan el nombre completo de cada usuario autorizado para acceder a la base de datos. Los campos "Usuario" y "Password" se encargan de identificar de manera única al usuario.

El campo "Dirección" almacena un número entero de 4 bits como máximo, que es empleado para identificar la vivienda del usuario. El campo correspondiente a "Revisión" es utilizado para determinar si se ha efectuado alguna modificación en la base de datos, por parte del usuario, y que aún no ha sido registrada por el sistema. Si se cumple que "Revisión=Mo" el usuario no ha efectuado ninguna modificación, en el caso que "Revisión=Si" el sistema se entera que se ha realizado algún cambio en el registro.

La segunda tabla (figura 6) consta de cuatro campos, de los cuales tres representan los electrodomésticos que pertenecen a los usuarios y el campo restante contiene información que enumera los registros existentes.

El primer registro del campo "identificador" es "Dirección"; este contiene, en forma horizontal, la dirección asignada a cada uno de los electrodomésticos con que cuenta el usuario. Los demás registros, ubicados en forma de columna, que hacen parte del campo "identificador" se emplean para determinar el estado (OM / OFF) actual del electrodoméstico, y contienen información que permite establecer si el usuario ha realizado una solicitud con respecto a un electrodoméstico en particular.

\section{INTERFAZ TRANSMISORA}

Conforme a lo planteado en el modelo de integración, debe existir un módulo físico que reciba del servidor la información 


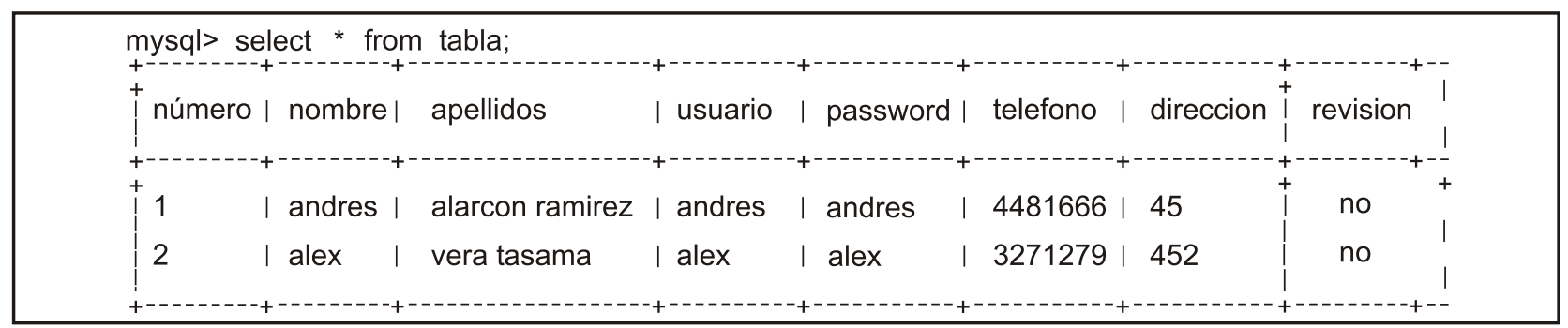

Figura 5. Visualización tabla de base de datos creada en MySQL para la identificación de usuario

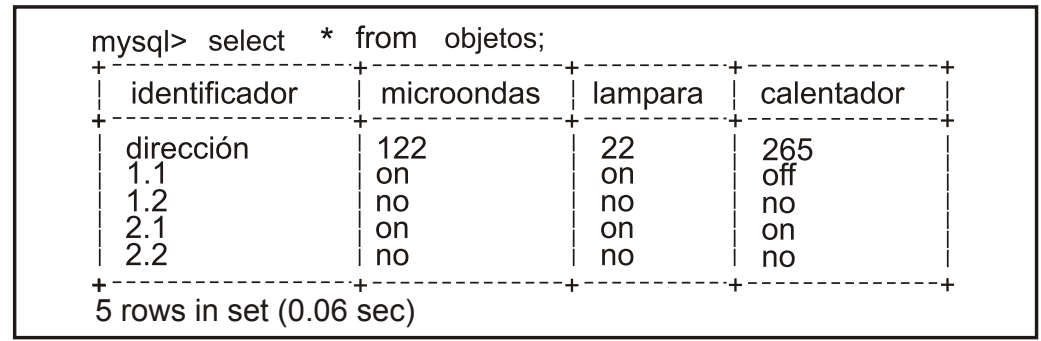

Figura 6. Visualización tabla de base de datos creada en MySQL para información de electrodomésticos

correspondiente a la identificación del usuario y de los equipos que va a controlar, así como la acción que se solicita sobre ellos, tal como se ve en la figura 7 .

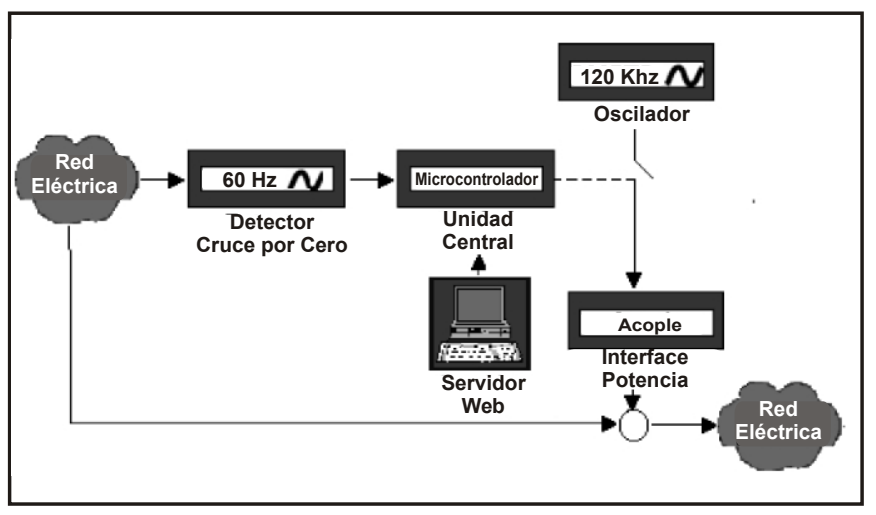

Figura 7. Diagrama de bloques del transmisor

Este módulo, establece una interfaz entre el programa residente en el servidor y la red eléctrica, hacia donde debe difundirse la información. El transmisor $X-10$ está conformado principalmente por un microcontrolador de Microchip (PIC16F873), cuyo programa debe esperar inicialmente que el servidor le suministre datos a través de su puerto serie (COM1), para generar los códigos correspondientes en términos del protocolo $X$ 10. Para hacerlo, debe detectar los cruces por cero de la señal de AC de la red, por lo que utiliza un hardware adicional basado en un transformador y en un comparador.

El microcontrolador genera un tren de pulsos, según los datos recibidos desde el servidor; cada pulso tiene una duración de $1 \mathrm{~ms}$. Con esto se pretende conmutar el paso de la señal producida por un oscilador senoidal (Puente de Wien) de $120 \mathrm{kHz}$, la cual debe introducirse en la red $A C$ en los cruces por cero correspondientes. El diagrama circuital del transmisor se puede apreciar en la figura 8. En la figura 8(a) se muestra la unidad central del transmisor en tanto que la figura 8(b) ilustra el transmisor.

\section{INTERFAZ RECEPTORA}

Se requiere de un hardware adicional por cada electrodoméstico potencialmente controlable. Este hardware corresponde a un módulo de recepción que detecte las secuencias $x$-10 presentes en la red eléctrica (ver figura 9). 


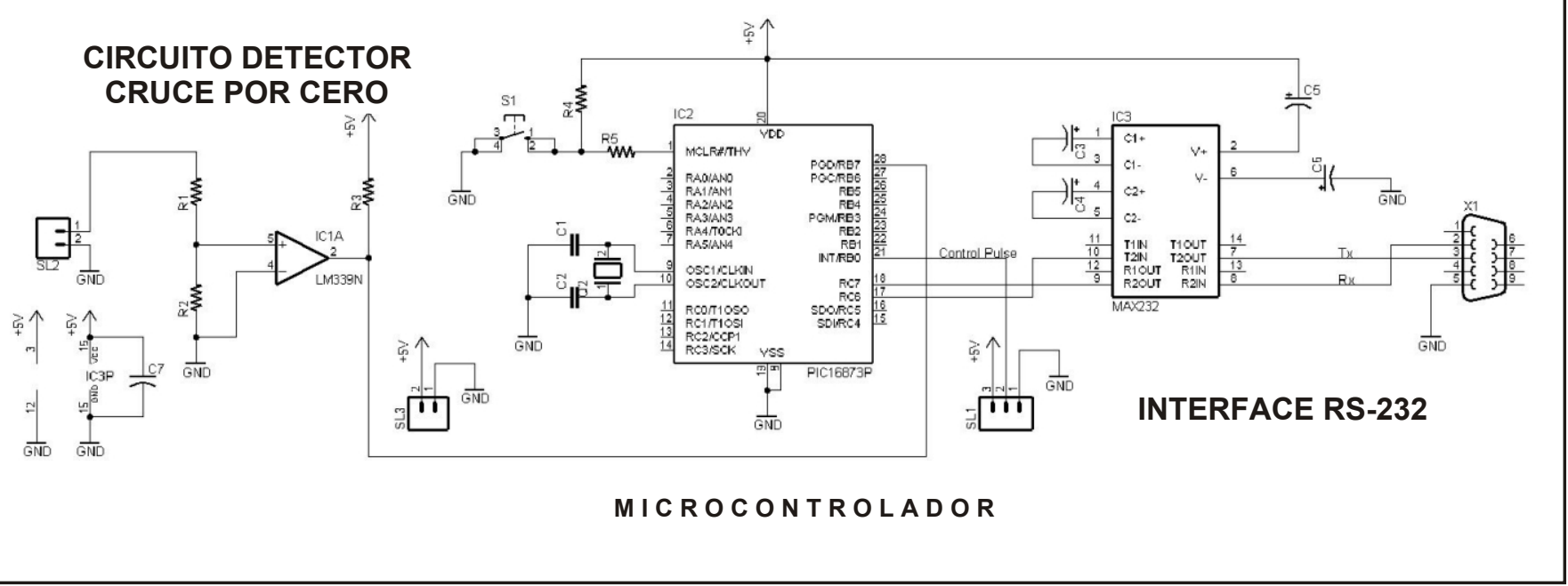

(a)

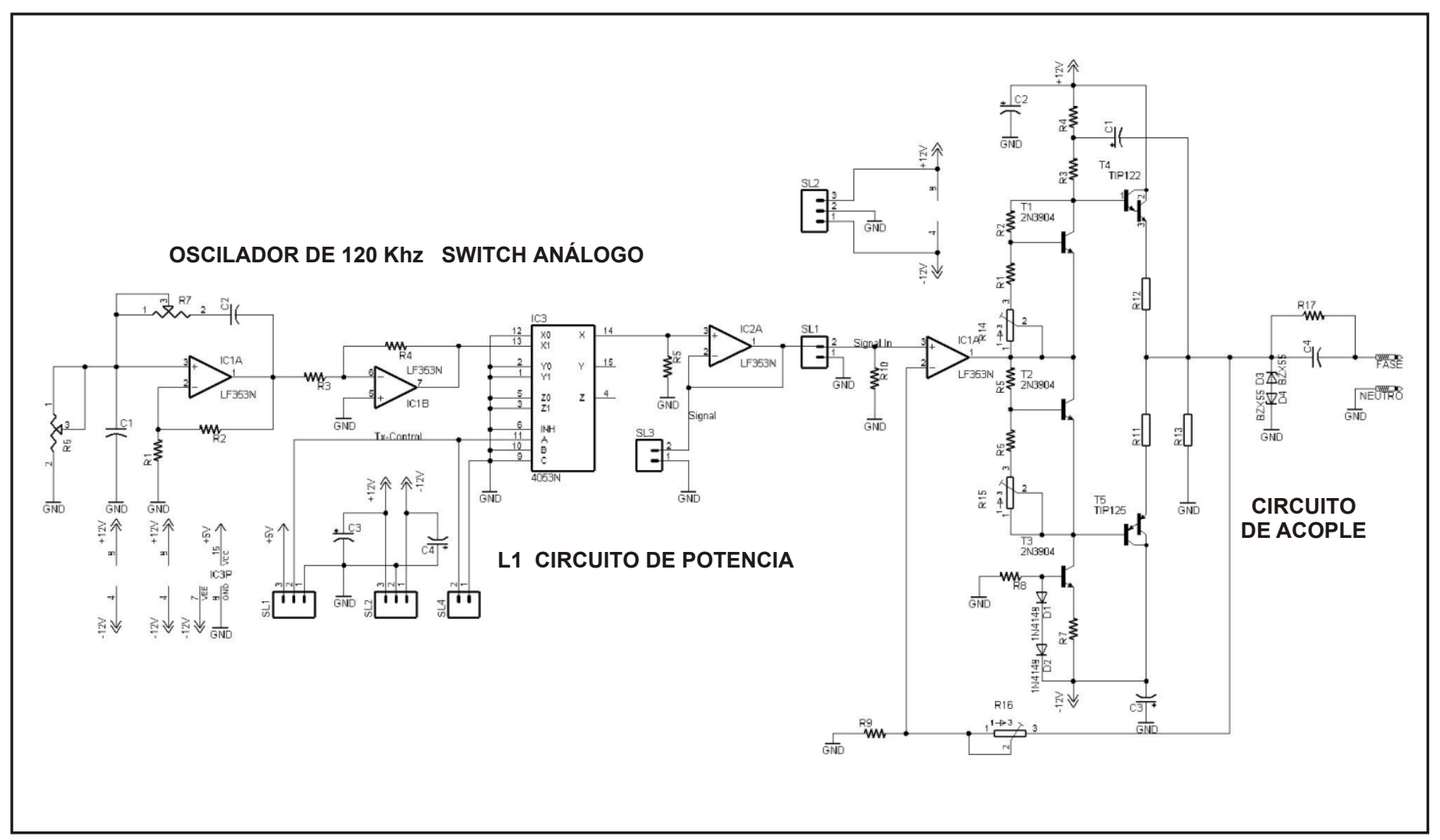

(b)

Figura 8. Diagrama circuital del Transmisor 


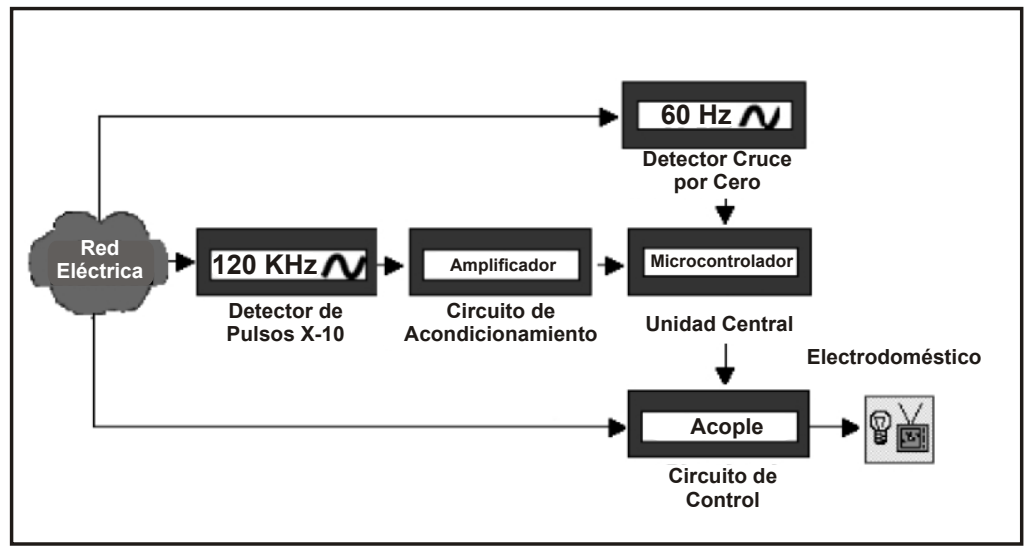

Figura 9. Diagrama de bloques del Receptor

El receptor, al igual que el transmisor, está basado en un microcontrolador de Microchip (PIC16F873), que recibe información en forma de trenes de pulsos de $120 \mathrm{kHz}$ sincronizados con los cruces por cero de la señal de la red eléctrica.

Esto se realiza a través de un circuito filtro y un detector de cruce por cero, que proviniendo de la red eléctrica le suministran al microcontrolador la información requerida para determinar la existencia de una secuencia de datos que represente alguna acción sobre el electrodoméstico a controlar. El accionamiento se lleva a cabo a través de una interfaz con relé, permitiendo el suministro o la interrupción de potencia al aparato eléctrico cuando el microcontrolador haya determinado respectivamente, el encendido o apagado del mismo. En la figura 10, aparece el diagrama circuital del módulo de recepción.

\section{FUNCIONAMIENTO DE LA INTERFAZ CELULAR - SERVIDOR}

En este proyecto, se emplea un simulador WAP, Deck It WML Previewer versión 1.2.3, para experimentar la comunicación entre el teléfono celular y el servidor. Esta herramienta de simulación es un programa que descarga una página editada en WML y emula la ejecución de la misma en un navegador de celular. La interfaz que ofrece este programa se puede apreciar en la figura 11 .

La página diseñada en WML, solicita al usuario un login y un password para la identificación del mismo. Una vez validado el usuario como poseedor del servicio, se muestran en pantalla los electrodomésticos que pueden ser controlados.

El usuario debe seleccionar aquellos sobre los cuales desea realizar alguna acción. A continuación, en otra pantalla, se muestran los electrodomésticos seleccionados por el usuario y se solicita la acción (OM OFF) a realizar. Por último, aparece un mensaje de confirmación para indicarle al usuario que su petición ha sido recibida. (Ver figura 12)

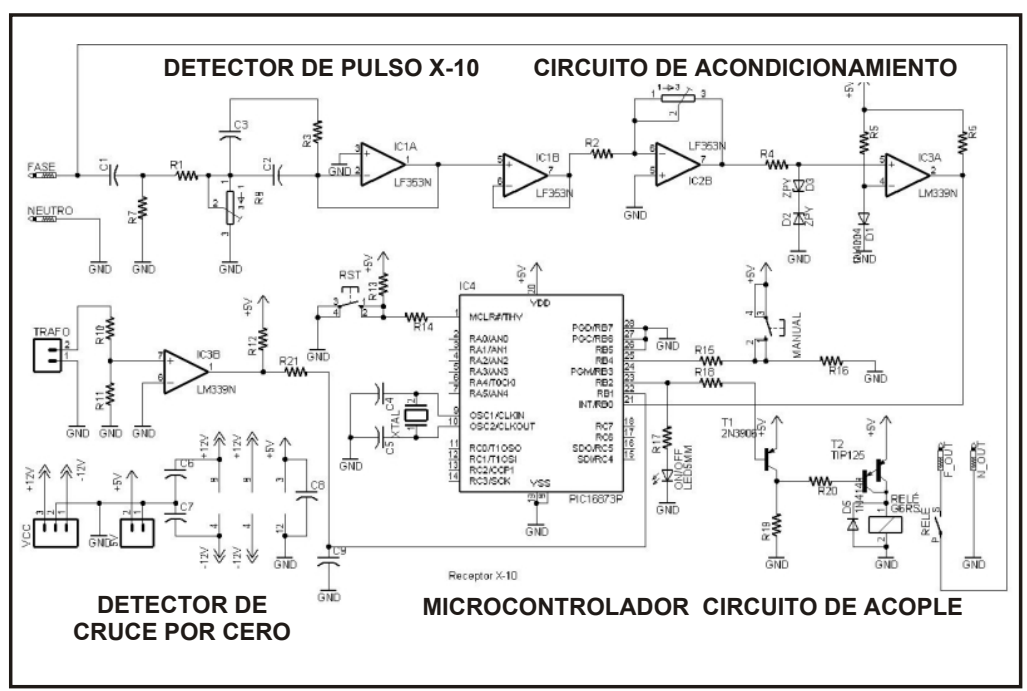

Figura 10. Diagrama circuital del receptor

\section{FORMAS DE ONDA DE LOS MÓDULOS DE TRANSMISIÓN Y RECEPCIÓN}

La señal generada por el microcontrolador (modulo transmisor), en respuesta a una orden de trasmisión impartida por el servidor se muestra en la parte izquierda de la figura 13. 


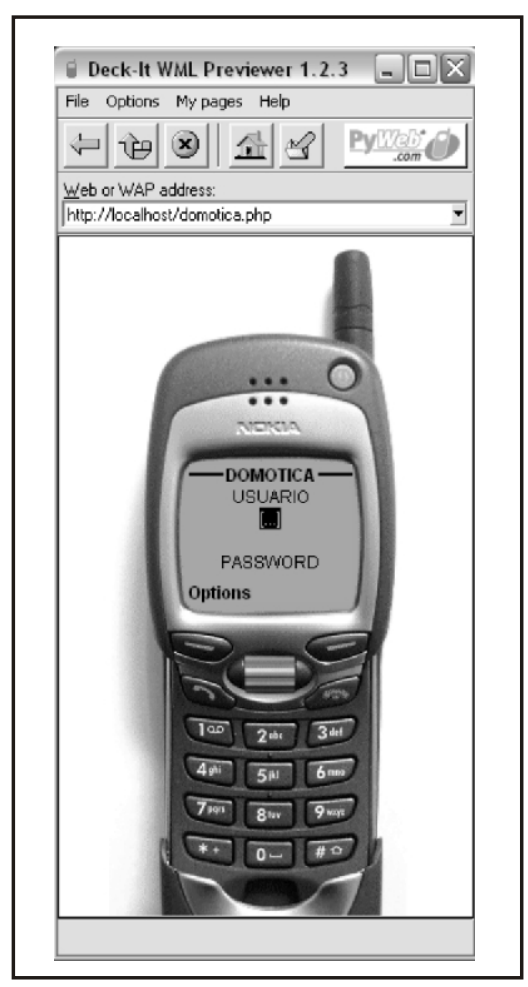

Figura 11. Interfaz gráfica del simulador WAP con la página diseñada en ejecución

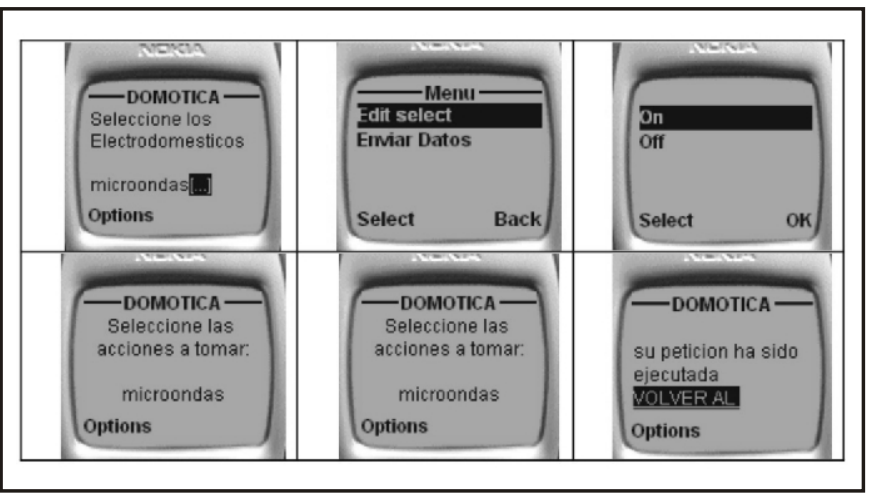

Figura 12. Visualización de la interfaz en el teléfono móvil - secuencia de ejecución

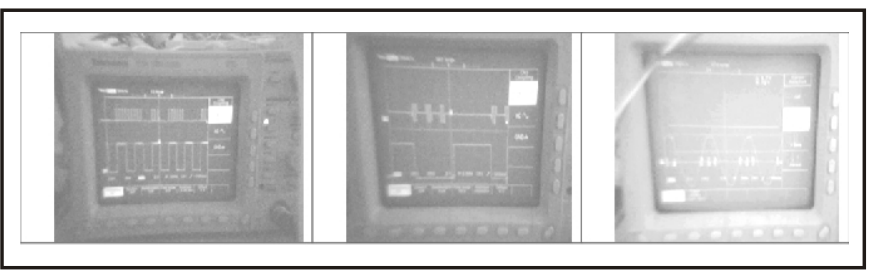

Figura 13. Señales recuperadas del Módulo Transmisor y receptor
Los pulsos generados por el modulo transmisor se muestran en la parte central de la figura 13. En cada cruce por cero se produce la transmisión de tres pulsos que coinciden con el paso por cero de las tres ondas senoidales presentes en un sistema trifásico.

La señal que corresponde a los pulsos de $120 \mathrm{KHz}$ filtrados de la red eléctrica, por el modulo de recepción se muestra en la parte derecha de la figura 13

\section{ALCANCES Y LIMITACIONES DEL MODELO DESARROLLADO}

La distancia máxima que puede ser alcanzada por el usuario que accede al servicio, presentado en este modelo, está determinada por el operador celular, el cual establece los rangos de cobertura del terminal móvil.

La transmisión que utiliza la tecnología X-10 presenta una gran limitante relacionada con las distancias que pueden alcanzar los datos que son enviados. Esto se debe a que utiliza como medio de transmisión la red eléctrica, la cual presenta circuitos de protección que filtran señales de alta frecuencia con el fin de que éstas no sean amplificadas y distribuidas a los demás usuarios conectados a la red. Por esta razón el modulo de transmisión se limita a enviar información a circuitos locales que se encuentran alimentados por una misma red eléctrica no afectada por la transformación de sus magnitudes de voltaje de distribución.

Otra limitante importante de esta tecnología tiene que ver con la influencia que realiza la carga puesta en la red eléctrica sobre las señales emitidas por el módulo transmisor (código X-10), puesto que los artefactos eléctricos emiten señales altamente contaminantes de la señal presente en la red eléctrica, es necesario transmitir con una suficiente potencia que garantice la llegada de una señal óptima a los receptores. 
El tiempo total empleado para realizar una acción de control sobre un electrodoméstico en particular, está determinado principalmente por el tiempo que requiere la comunicación entre el teléfono móvil y el servidor, y el que tarda una secuencia de datos en llegar al receptor desde el momento que es enviado por el de transmisor $x$ 10.

El primero de ellos depende principalmente de la velocidad de conexión que es ofrecida por el proveedor de servicios del terminal móvil.

El tiempo de transmisión X-10, está limitado por las condiciones del protocolo, el cual establece una velocidad de 60 bps, empleando un tiempo de 0.783 s para transmitir una trama de datos $X$ 10. Aunque esta velocidad no es muy alta, no constituye una limitación importante para esta aplicación, donde el tiempo no es critico.

\section{CONCLUSIONES}

La gran popularidad que han adquirido los teléfonos móviles últimamente, ha generado que las compañías que prestan este servicio incorporen nuevas tecnologías que permita ofrecer a sus usuarios un mayor número de servicios como son el acceso a Internet, buzones de voz, agendas, entre otras.

El empleo de la tecnología $X-10$ en sistemas domóticos facilita la creación de aplicaciones que brindan comodidad y que permiten su adaptación a necesidades y requerimientos de cualquier tipo de hogar.

La utilización del modelo desarrollado no se limita únicamente al uso exclusivo en la domótica, y puede ser adaptado a cualquier tipo de control industrial que requiera ser realizado en forma remota.

\section{BIBLIOGRAFÍA}

[1] Amgulo usategul, josé $M^{a}$. Microcontroladores PIC. Diseño práctico de Aplicaciones. Mc. Graw Hill, Madrid España. 1999. 295 p.

[2] DUQUE C., Edison. Curso Avanzado de Microcontroladores PIC. Cekit S.A. Pereira Colombia. 1998. $172 \mathrm{p}$.

[3] LUMA OSORIO, Sadat Karim y AYALA BELTRAM, Jorge Alonso. Aportes de la Tecnología WAP para acceder redes públicas o privadas. Santiago de Cali, 2001, 317p. Trabajo de grado (Ingeniero Electrónico): Universidad del Valle. Facultad de Ingeniería.

[4] MAMCILLA MARTIMEZ, Marcial. Estudio del protocolo X-10. Santiago de Cali, 1998, 105p. Trabajo de grado (Ingeniero Electrónico): Universidad del Valle. Facultad de Ingeniería.

[5] http://www.casadomo.com

[6] http://www.domotica.net

[7] http://energiaycomputacion.univalle. edu.co/edicion19/revista19_10a.phtml 